\title{
Deep Electrical Resistivity Tomography for the Hydrogeological Setting of Muro Lucano Mounts Aquifer (Basilicata, Southern Italy)
}

\author{
E. Rizzo $\mathbb{D}^{1},{ }^{1}$ V. Giampaolo, ${ }^{1}$ L. Capozzoli, ${ }^{1}$ and S. Grimaldi ${ }^{2}$ \\ ${ }^{1}$ CNR-IMAA, Laboratorio Hydrogeosite, Tito-Marsico Nuovo, Italy \\ ${ }^{2}$ Department of Science, University of Basilicata, Potenza, Italy \\ Correspondence should be addressed to E. Rizzo; enzo.rizzo@imaa.cnr.it
}

Received 19 July 2018; Revised 15 November 2018; Accepted 2 December 2018; Published 27 February 2019

Guest Editor: Mari L. García-Lorenzo

Copyright (C) 2019 E. Rizzo et al. This is an open access article distributed under the Creative Commons Attribution License, which permits unrestricted use, distribution, and reproduction in any medium, provided the original work is properly cited.

\begin{abstract}
The proposed work concerns the application of a deep geoelectrical survey to a carbonate aquifer in order to define the best location for exploitation well drilling for increasing water supply. However, an optimal characterization of a groundwater resource is the necessary condition to reach the indicated aim. Therefore, the geoelectrical investigation was guided from the previous geological and hydrogeological characterization. Moreover, geophysical methods are good tools to improve the groundwater model when detailed information is necessary, such as the localization of a pumping well. The work summarizes the hydrogeological knowledge at the West of the Basilicata Region (Muro Lucano, Italy). The investigated area is characterized by the presence of a karst aquifer which is made up of a carbonate ridge (Castelgrande, Muro Lucano) that tectonically dips southward and is widely covered by Pliocene deposits (sands and conglomerates), by the Irpinian unit and Sicilide unit formations, and by debris slope and landslide deposits. The assessment of the complex hydrogeological framework of the area was detailed by the use of a new multichannel deep geoelectrical technique (DERT). In details, the proposed technique was able to successfully locate a less resistive zone connected to a more fractured limestone and then it was suitable for the localization of a groundwater exploitation well.
\end{abstract}

\section{Introduction}

Hundreds of millions of people worldwide live in karst areas and are supplied by drinking water from karst aquifers. In particular, the karst aquifer map of Europe shows that $21.6 \%$ of the European land surface is characterized by the presence of (continuous or discontinuous) carbonate rocks; about $13.8 \%$ of the land surface is carbonate rock outcrop $[1,2]$. Karst carbonate aquifers play an extremely important role in water supply, irrigation, and power generation due to the exceptional water quality and quantity. At the same time, they are a very vulnerable and dynamic system due to their peculiar features [3]:

(i) Heterogeneity: the properties of karst aquifers greatly vary in space (ii) Anisotropy: the aquifer hydraulic properties depend on the orientation of geologic fabric elements (the hydraulic conductivity is typically high in the direction of large fractures and conduits, but may be low in other directions)

(iii) Duality of porosity and flow: there are two or even three types of porosity in karst aquifers (rock matrix, fracture, and conduit porosity), whereas groundwater flow in the matrix and small fissures is typically slow and laminar and flow in karst conduits (caves) is often fast and turbulent

(iv) Variability: at karst springs, discharge variations by factors of 10 to 100 within hours or days are common, and karst springs typically show also rapid variations of water quality 
In particular, the geological structures and the local lithological variations play an important role in karst system, where various depositional and diagenetic processes and fracture distribution can produce a wide range of conduit size. These features make a karst aquifer very complex, so for these reasons, they require increased protection and application of innovative methodologies for their investigation.

For these reasons, in recent years, the use of geophysical investigations in karst regions has increased rapidly with the aim of (i) giving more detailed information on underground karst morphology characteristics (detecting and characterizing caves and fractures) and (ii) understanding karst hydrogeological functioning, as a support to hydrogeochemical information $[4,5]$. These techniques have the advantage of greater spatial resolution, lower costs, simpler field procedures, and more rapid inversion and interpretation of data [6].

To date, the geophysical methods most used in a karst environment are geoelectrical, electromagnetic, gravimetric, and seismic [5, 7-9]. Seismic methods are the most suitable to delineate geological boundaries and the external geometry of the aquifer. Gravity can be used to identify large voids, such as potential sinkholes, as well as caves and major karst conduits [9-15]. Moreover, geoelectrical and electromagnetic methods, by determining lateral and vertical variations in subsurface electrical resistivity, are useful to identify geological and hydrogeological features, such as caves, fractures, and sinkholes, and are particularly sensitive to the presence of subsurface water [16-21].

In particular, the use of electrical resistivity tomography (ERT) for karst system exploration has considerably increased in the last 10 years $[5,8,9,20,22-25]$. The strength of such methods resides in their effectiveness to track changes in the electrical properties of the subsurface, reflecting petrophysical and hydrologic property variations such as porosity, hydraulic conductivity, fluid content, temperature, presence of clay, salinity, presence of contaminants, and biodegradation activity [26-33]. For these reasons, electrical resistivity surveys are the best known geophysical techniques in hydrogeological context for groundwater characterization and monitoring.

For porous media fully saturated by brine, Archie [34] proposed a simple correlation between bulk resistivity and pore resistivity depending on formation factor $F=\varphi^{-m}$, where $\varphi$ is the porosity and $m$ is the cementation exponent. The validity of Archie's equation was verified in many papers ([34, 35]; Wyllie, 1960; [6, 36-39]). However, many measurements showing a poor fit with Archie's equation have been reported, especially in the case of carbonate rocks characterized by primary, secondary (fractures and faults), and conduit porosity [40].

Fracture geometric characteristics such as fracture intensity, fracture network connectivity, and aperture distribution are crucial features controlling the hydraulic and geotechnical properties of rock formations. In particular, Kirkby et al. [41] and Roubinet et al. [42] explore the relationship between electrical resistivity and permeability in a fracture filled with an electrically conductive fluid by accurately modeling of fracture opening. They found that at small apertures, electrical conductivity and permeability increased moderately while, at the percolation threshold, defined in terms of the matrix to fracture resistivity ratio, for fracture networks surrounded by a low-porosity matrix, very small changes in aperture are associated with large changes in both the conductivity and permeability of the fracture. The position of this threshold depends on the rock and fluid resistivity and properties of the fracture. Therefore, small changes in the fracture network characteristics may be leading to large changes in both the rock resistivity and the permeability.

In order to increase resolution for deeper target, Deep Electrical Resistivity Tomography (DERT) approach (investigation depth $>200 \mathrm{~m}$ ) can be used. It was described for the first time by Hallof [43], which was able to reach an investigation depth greater than $200 \mathrm{~m}$, and consists in the use of physically separated tools between the injection system and the measured drop of a potential tool. Even if the Deep Electrical Resistivity Tomography (DERT) method is considered a geophysical approach for deep groundwater studies, it is not a common system for a deep hydrogeological target $(>200 \mathrm{~m})$. In fact, only few examples are reported in the literature [44-52].

Usually, in order to obtain the electrical resistivity distribution of a deep target, the magnetotelluric (MT) and control source audio magnetotelluric (CSAMT) are the most used electromagnetic methods, but due to their low resolution, their aim is usually connected with deeper geological target, such as tectonic faults, crustal studies, and geothermal and oil reservoir detection $[53,54]$.

In this paper, we focus our attention on the analysis of hydrogeological and electrical resistivity data, acquired by a new deep ERT (DERT) system, to have an image of Muro Lucano Mounts buried hydrogeological structures and to understand the deep water circulation system. The definition of the resistivity distribution allowed us to obtain important information on the hydrogeological characteristic of the deep aquifer.

\section{Geological Setting}

The carbonate aquifer of Muro Lucano is located in the $\mathrm{NW}$ of Potenza district (Basilicata region) and in the NE portion of the Marzano-Ogna carbonate massif in the central sector of Southern Apennines thrust-and-fold belt, between Basilicata and Campania regions (Figure 1). The investigated zone covers an area of about $40 \mathrm{~km}^{2}$, and some sectors are characterized by outcropped carbonate (Castelgrande-Muro Lucano ridge). The mean elevation is 870 m.a.s.l., and the morphological setting shows a typical tectonic valley extended in the NW-SE direction.

Southern Apennines are a NW-SE trending chain formed between the upper Oligocene and Quaternary [55] as a response to convergence between the African plate and the European and contemporary retreat towards the SE of the ionic subduction $[56,57]$. Since the Middle Miocene, compressional deformation was responsible for the building up of a pile of rootless nappe. Mesozoic carbonates of the Western carbonate platform overthrust coeval pelagic sequences 


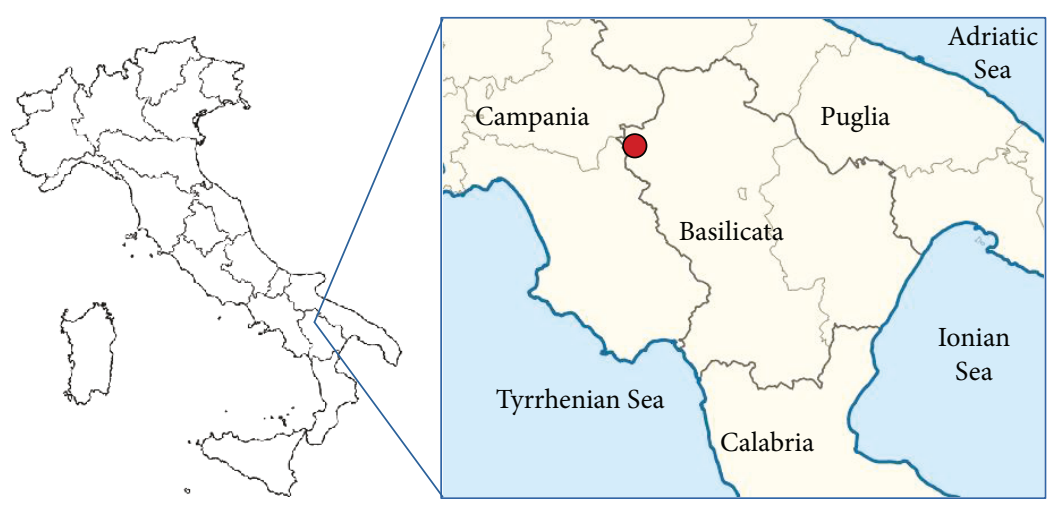

FIGURE 1: Localization of the investigation site.

of the Lagonegro basin, which in turn overlays tectonically deeply deformed Mio-Pliocene foredeep deposits [58]. Liguride-Sicilide units, from a basin domain located west of the Western carbonate platform, systematically overly both the carbonates and the Lagonegro units.

This stack of thrust sheets overthrusts with an overall E-vergence shelf limestones of the Apulia platform up to $7 \mathrm{~km}$ thick that underwent thick-skinned tectonics during Late Pliocene to Early Pleistocene times [59]. The detachment between the allochthon and the buried Apulian unit is marked by a mélange zone, generally several hundreds of meters thick and locally exceeding a kilometre in thickness [58].

In the nearest of the studied area, the complex thrust-and-fold system has been deeply explored by the commercial seismic reflection profile CROP $04[60,61]$ and two deep wells (San Gregorio Magno and San Fele). In particular, the Muro Lucano carbonate massif develops in the Meso-Cenozoic carbonate substratum of the Mt. Marzano-Maddalena Mounts unit (Apennines platform) overthrusted over Lagonegro unit terrain (Figure 2). The unit is formed by a powerful limestone dolomite succession of approximately $2000 \mathrm{~m}$, aged between the Late Triassic and Early Eocene [62]. In the studied area, the carbonate succession is represented mainly by the Jurassic limestones and dolomitic limestones and by Cretaceous calcarenites, calcirudites, and carbonate breccias, which indicate that the sedimentation occurred at an escarpment that connected the Apennines platform with the Lagonegro basin [61]. Lagonegro II unit outcrops in the northeastern sector (Figure 2) constituted of middle Triassic to lower Cretaceous basin marine deposits with abundant shallow water-derived carbonate material (siliceous schists, galestrino flysch, and red flysch). Sicilide units (blue-gray clays) are localized in the W, and Irpinian units [63] are instead defined in the $\mathrm{N}$ and $\mathrm{W}$ and in the $\mathrm{S}$ between Monticello and Paratiello mountains (Figure 2).

In particular, Irpinian units are represented by calcarenites and limestones alternated to small layers of green and yellow clays and they were deposited from Burdigalian to Tortonian in a basin called the Irpinian basin, a wide Miocene Apennines chain foredeep. Finally, the syntectonic unit of the Muro Lucano basin (sand and polygenic conglomerates of lower Pliocene) covers the previous units by an unconformity. It is constituted mainly by sands and sandstone of medium to lower Pliocene. In the $\mathrm{NE}$ zone, the carbonate rocks generated debris slope deposits with huge thickness and extension.

The Monte Marzano-Ogna carbonate massif is bounded at south-west by high-angle $\mathrm{N} 120^{\circ}$-trending left-lateral strike-slip faults and low-angle E-trending, N-dipping normal faults [64]. Some of these faults are active and reflect the present day extensional tectonic field responsible for the 1980 Irpinian earthquake and of other strong historical earthquakes, with epicentral intensity between IX and XI MCS, such as those of 990, 1561, 1694, and 1857 ([64] and references therein). Finally, the northern sector the carbonate massif is bounded by a low-angle thrust fault where the carbonate units overlay Lagonegro terrains.

In particular, the Muro Lucano carbonate massif shows a lens shape, which is extended $14 \mathrm{~km}$ in the E-W direction. According to Scandone et al. [60] and Scrocca et al. [61], the outcropping carbonate is constituted by undifferentiated Apennines platform terrains (chaotic complex) characterized by highly fractured and tectonized (cataclasites) limestones; it is partially buried by Muro Lucano basin units (sand-clay and conglomerates) and is bounded by two low-angle thrust faults. The structural survey of the main systems of fractures of the rock massif at the north of the Muro Lucano town highlighted the prevalence of high-angle $\mathrm{N} 30-50^{\circ}$ and $\mathrm{N}$ $160-170^{\circ}$ systems and subordinated the presence of other systems, among which is the $\mathrm{N} 90^{\circ}$. In several points, fractures are open to some tens of centimeters [65].

The eastern part of the carbonate structure is characterized by gravitational phenomena caused by neotectonic movements along active faults. Some of these, generally rockfalls, are associated to historical earthquakes (1561, 1857, and 1980) described above [66].

\section{Methodology: Deep Electrical Resistivity Tomography (DERT)}

The electrical resistivity tomography is largely applied in small-scale investigations to solve environmental and engineering problems. Recently, the improvements in the field technology and data processing allow us to apply this method 


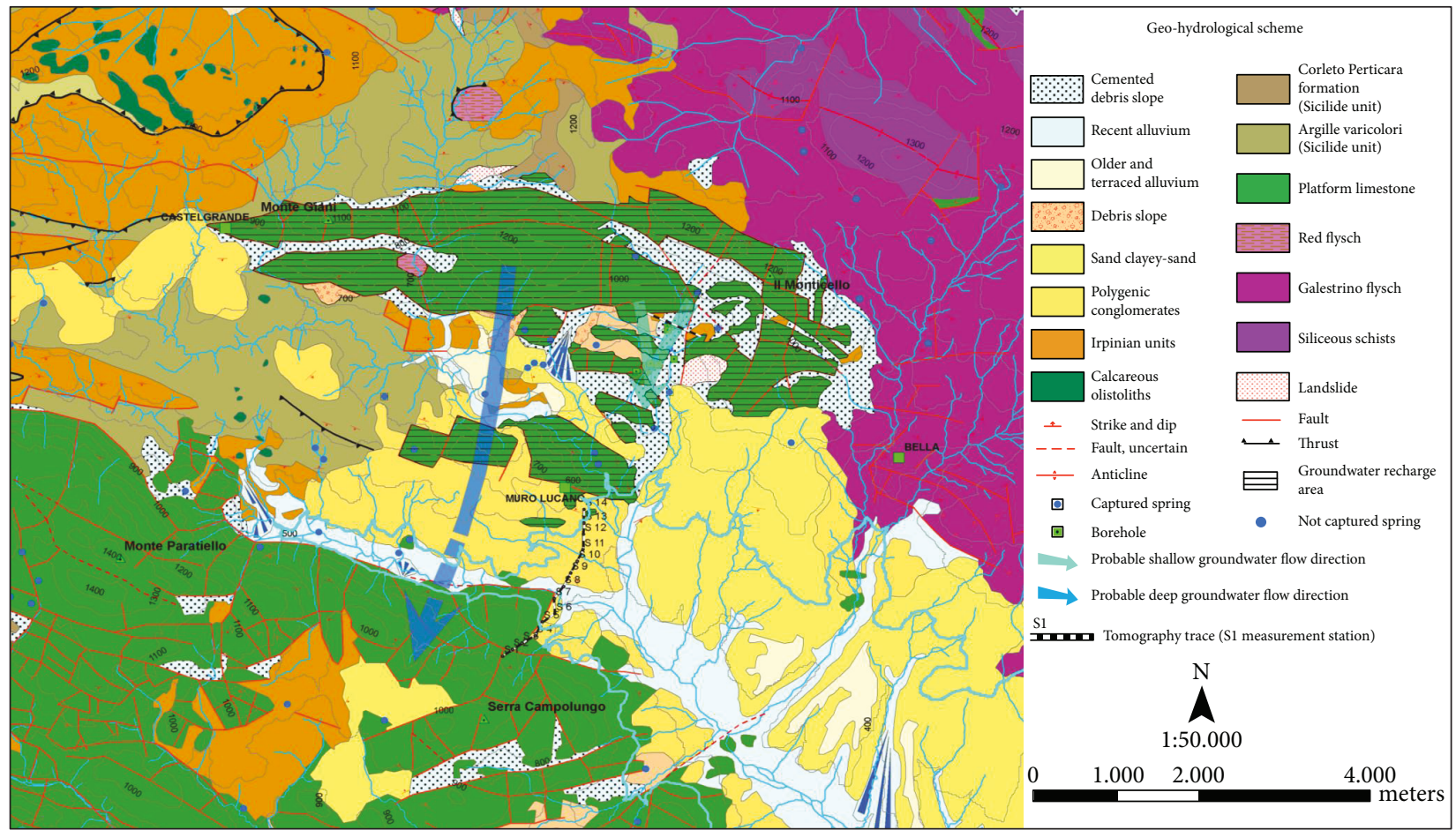

(a)

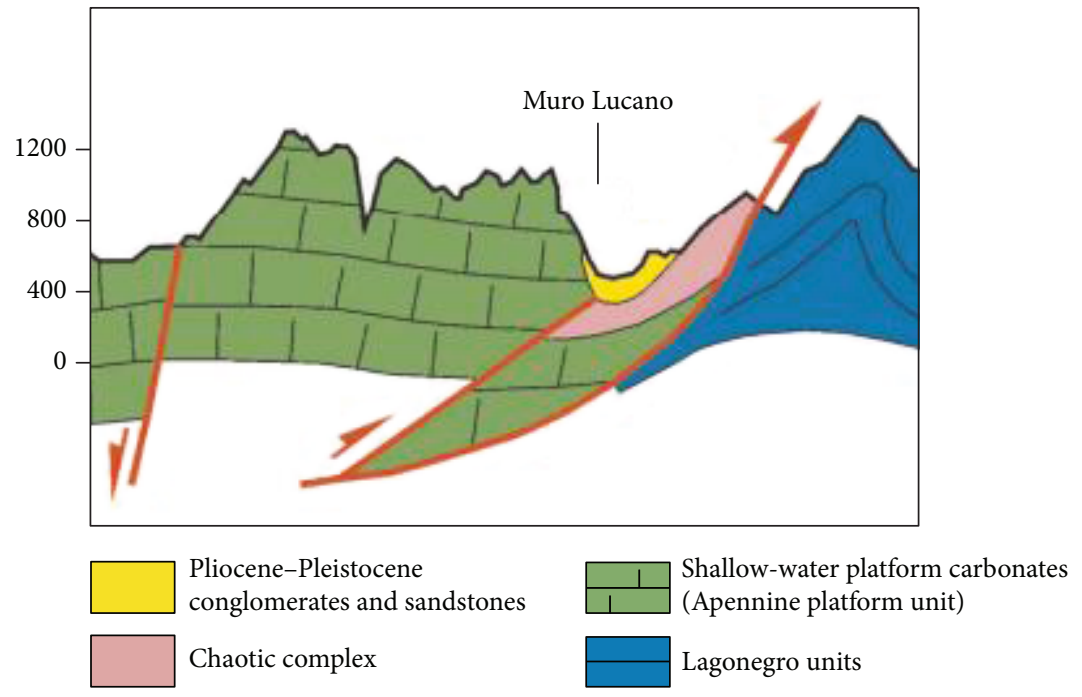

(b)

Figure 2: (a) Geological map with hydrogeological features. (b) Cross-section of the shallow geological structures along the Crop 04 deep seismic profile from San Gregorio Magno to San Fele. Modified by Scandone et al. [60].

in the large-scale investigations for geological structural studies [44, 45, 48-50]. In order to define the best location for deep drilling exploration well for having a low ratio between the economic effort and water pumping capacity, a Deep Electrical Resistivity Tomography was carried out in the investigated area (Figure 2).

It was used as a dipole-dipole array configuration, where the electric current $(I)$ is sent into the ground via two contiguous electrodes $x$ meters apart $(200 \mathrm{~m})$, and the potential drop $(\Delta V)$ is measured between two other electrodes $x$ meters apart in line with the current electrodes $(200 \mathrm{~m})$.
The spacing between the nearest current and potential electrodes is an integer $n$ times the basic distance $x$ and the maximum number of measurements $n$ depending from the signal-to-noise-ratio of the voltage recordings [67]. In this way, the electrode array geometry allows us to obtain a length of the deep electrical survey of $2600 \mathrm{~m}$, with an exploration depth of about $350 \mathrm{~m}$. The acquisition system (a prototype system built in the Hydrogeosite Laboratory of CNR-IMAA, Figure 3) consists of a transmitting station which injects the current (5-10 amperes) into the ground and a new multichannel receiver device which records the generated voltage 


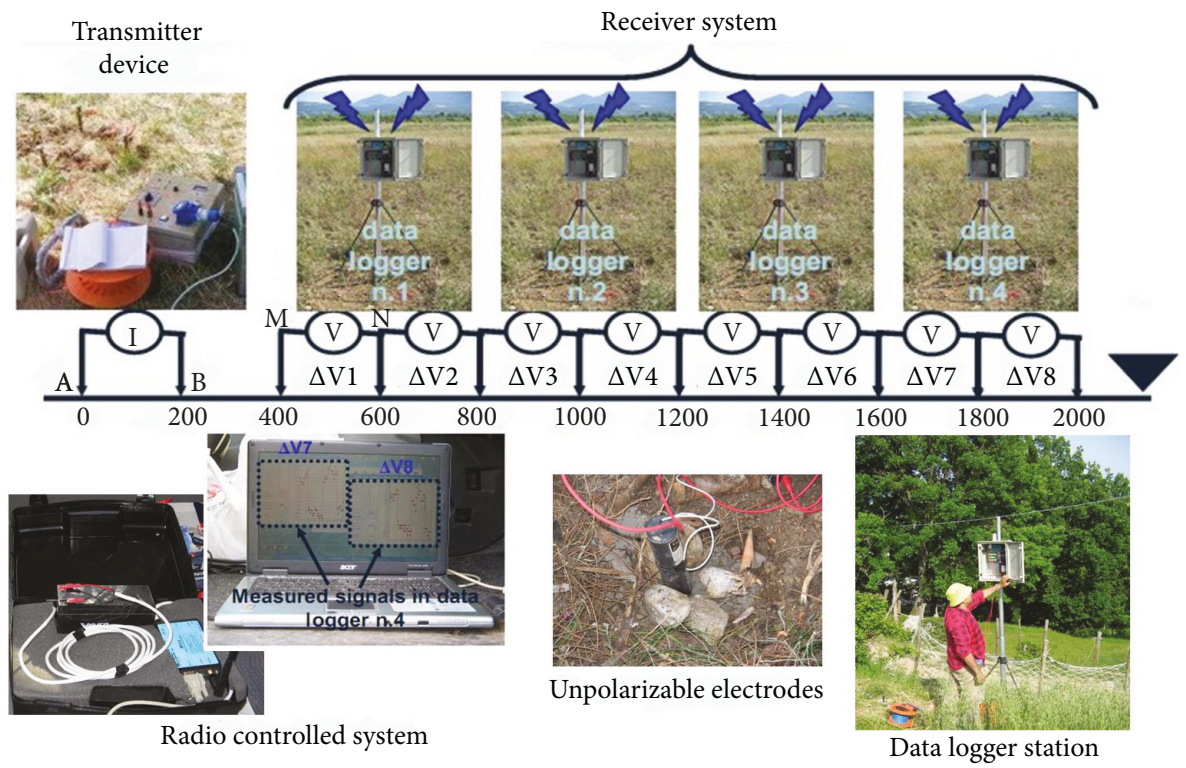

FIGURE 3: Geoelectrical prototype for Deep Electrical Resistivity Tomography, made by CNR-IMAA.

signals $(\mathrm{mV})$. The receiving system is composed of 4 remote multichannel data loggers connected with a radio communication system to a personal computer. Therefore, at the same time, 8 voltage recordings from 5 to $20 \mathrm{~min}$ were acquired for each current injection related to different positions of the electrodes along the profile. Overall, we collected 56 voltage recordings.

The second step consisted in the extraction of the useful signal from voltage recordings to calculate the apparent resistivity values. In fact, in deep geoelectrical explorations, a crucial task is the extraction of useful signal from voltage recordings, taking into account that the signal-to-noise ratio depends on the distance between the current emitters and receivers. However, the quality of the signal also depends on the spacing between electrodes, worsening as the receiving dipole moves away from the energizing one. The distribution of electrical conductivity in the soil also affects the quality of the signal; in fact, in highly conductive areas, located between the transmitting and receiving dipoles, the electric potential is strongly masked to such an extent that the signal is completely erased from the background noise. Therefore, the success of the methodology is related to the duration of voltage recordings.

For the elaboration of acquired data, we used OriginPro software (OriginLab Corporation) where graphing and data analysis tools were used. The first step of the voltage data analysis was the spike removing, which consists to delete the spikes on the active graph window. The second step was the detrending analysis, which consisted in a polynomial or linear fit of the voltage data and a subsequently detrend approach, in order to remove the natural trend that enveloped the data. Successively, a FFT tool was performed to the detrending voltage data. The amplitude of the FFT results in the frequency of the acquired signal defines the amount of the drop of potential. A good signal-to-noise ratio, in the FFT spectrum of signal amplitudes, produces a peak right at the energization frequency (which in our case was equal to $0.025 \mathrm{~Hz}$ ). On the contrary, the spectrum of particularly noisy voltage signals presented a series of "spikes" that make the identification of the useful signal much more complex. At the end of the data analysis steps, the estimated voltage $(\Delta V)$, the injected current $(I)$, and the position of each quadripole (geometric coefficient) permitted us to calculate the apparent resistivity $\left(\rho_{a}\right)$ by the Hannenson formula:

$$
\rho_{a}=[\operatorname{\pi an}(n+1)(n+2)]\left(\frac{\Delta V}{I}\right)
$$

where $a$ is the electrode distance $(200 \mathrm{~m}$ in this investigation) and $n$ is the pseudodepth level $(\max n=7$ in this investigation).

Resistivity measurements are associated with varying depths depending on the separation of the current and potential electrodes in the survey and can be interpreted in terms of a lithological and/or geohydrological model of the subsurface. Measured data are the apparent resistivity because the resistivity values measured are averages over the total current path length but are plotted at one depth point for each potential electrode pair (Figure 4). Twodimensional images of the subsurface apparent resistivity variation are called pseudosections. Data plotted in crosssection is a simplistic representation of actual, complex current flow paths. Inversion software then helps to interpret geoelectrical data in terms of more accurate earth models. The inversion and optimization processes of the recorded values along the long longitudinal profile were executed by means of the ZondRes2D software (Zond geophysical software). It is a computer program for $2.5 \mathrm{D}$ interpretation of electrical resistivity tomography, and the finite-element method as the mathematical apparatus is used to solve a forward and inverse procedure. The first step was to prepare 


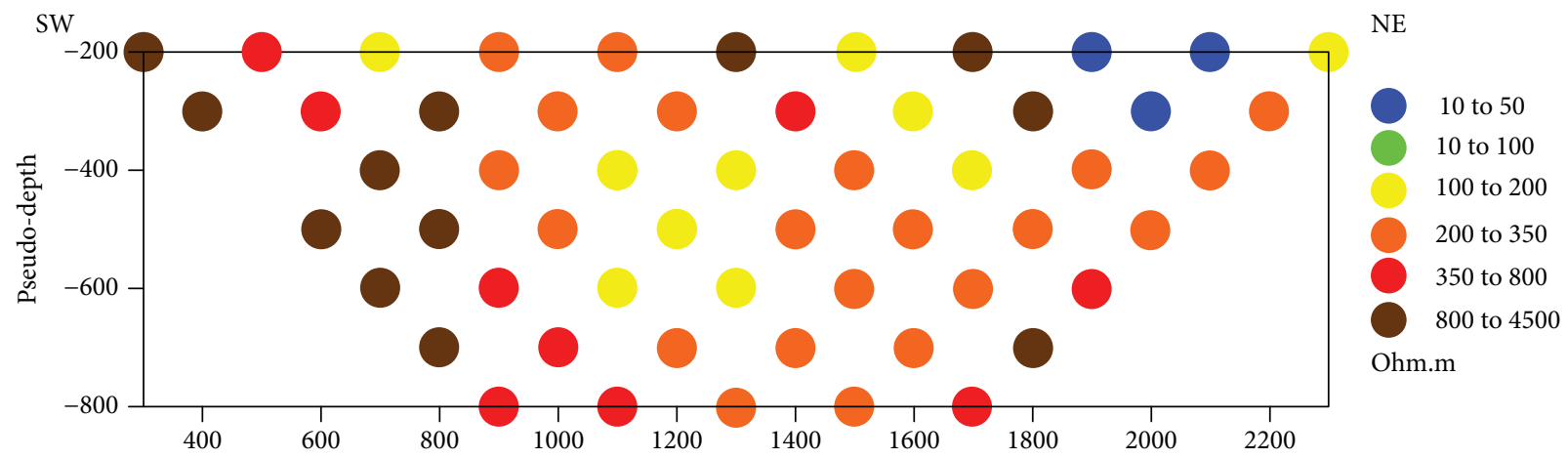

FIgURE 4: Distribution of the calculated apparent resistivity value.

the data for the inversion, such as poor data detection. The next step was to select the inversion type and parameters. In order to transform the apparent resistivity pseudosection into a model representing the distribution of calculated electrical resistivity in the subsurface, we used the smoothness constrained that is an inversion by a least-square method with the use of a smoothing operator. The inversion type was the Marquardt classic inversion algorithm consisted in a least-square method with regularization by a damping parameter [68]. In case of little quantity of section parameters, this algorithm allows receiving a contrast subsurface model. In order to follow the inversion algorithm, the data set was inverted by using a $100^{*} Y \mathrm{~m}^{2}$ cell size, where $Y$ is the vertical dimension which is a variable from $20 \mathrm{~m}$ and an increase factor of 1.10 for 13 levels. The starting homogeneous model was with an apparent resistivity of $100 \Omega \mathrm{m}$, and the final RMS was $12.8 \%$.

\section{Results and Discussions}

Figure 5 shows the resistivity distribution, where a resistivity range from $50 \Omega \mathrm{m}$ to more than $2000 \Omega \mathrm{m}$ is defined. In the resistivity image, it is possible to distinguish some main electrical layers. A shallow resistivity layer $(>800 \Omega \mathrm{m})$ is recognizable from about $900 \mathrm{~m}$ and $2000 \mathrm{~m}$ of horizontal displacement from the origin up to the end of the profile. This electrolayer has a different thickness of around $100 \mathrm{~m}$ maximum. Under the shallow resistivity layer, it is possible to distinguish a relative conductive zone until 100 m.a.s.l. $(<200 \Omega \mathrm{m})$. This electrolayer is located above a deep resistivity layer $(>800 \Omega \mathrm{m})$ which is well highlighted along the whole tomography up to 100 m.a.s.l., and it is outcropped on the NE flank.

The not easy geological interpretation of the geophysical results reflects the complex geological setting of the investigated area characterized by the superimposition of different tectonic phases. Generally, the DERT image is characterized by relative resistive electrical values that can be associated to the carbonate formation (high resistivity). Moreover, a detailed qualitative analysis of the resistivity tomography highlights some hydrogeological features, just due to the strong correlation between the fluid in the fractures and the electrical resistivity. The relatively high resistive zone (shallow and deep) should be characterized by a nonsaturated carbonate, while the medium electrolayer, characterized by relatively low resistive values $(<200 \Omega \mathrm{m})$ should be associated to a saturated carbonate, due to a different fracturing degree. Lateral resistivity contrast is probably marked by tectonic contact.

A first geophysical and hydrogeological analysis suggested a high potential for exploiting the Muro Lucano carbonate aquifer. In particular, from a hydrogeological point of view, all the edges of the studied carbonates are boarded by faults and are plugged by Sicilide and Irpinian units characterized by low to medium hydraulic conductivity material. On the contrary, Muro Lucano and Monte Marzano carbonate massifs are characterized by a high permeability degree linked to an intense fracture network and karst features, such as sinkholes and caves, as testified by the presence, in the southern sector, of a karst system of active caves with a total length of more than $1500 \mathrm{~m}$. Finally, the Muro Lucano unit terrain is characterized by medium to high permeability degree.

Moreover, it is possible to speculate two main groundwater flows: a very shallow one and a deeper one. The shallow water circulation is imposed in the Pliocene sands and conglomerates and is indicated by several springs and by the presence of several saturated shallow ground zones. A water capacity of about 20-301/s was estimated (data from the Water Protection Plan of Basilicata Region). On the contrary, the studied carbonate structure is lacking in basal springs and meteorological precipitations (with an average annual value of $907 \mathrm{~mm}$ recorded in the 20002004 period) do not produce a considerable increment of the discharge in the basal rivers (Forra di Muro river, etc.). Therefore, it is possible to consider the presence of a deep water circulation.

A lack of detailed knowledge on Muro Lucano buried aquifer characteristics, identification of areas with high recharge potential, dominant fracture and/or conduit porosity zones, and well-defined geological boundary conditions can hamper the ability to exploit the groundwater resources. However, taking into account the geophysical results and the most favorable topographic position, it was possible to localize the best site of an exploration well for water supply research.

In particular, the well was installed along the geoelectrical profile at $1100 \mathrm{~m}$ of horizontal displacement from the origin 


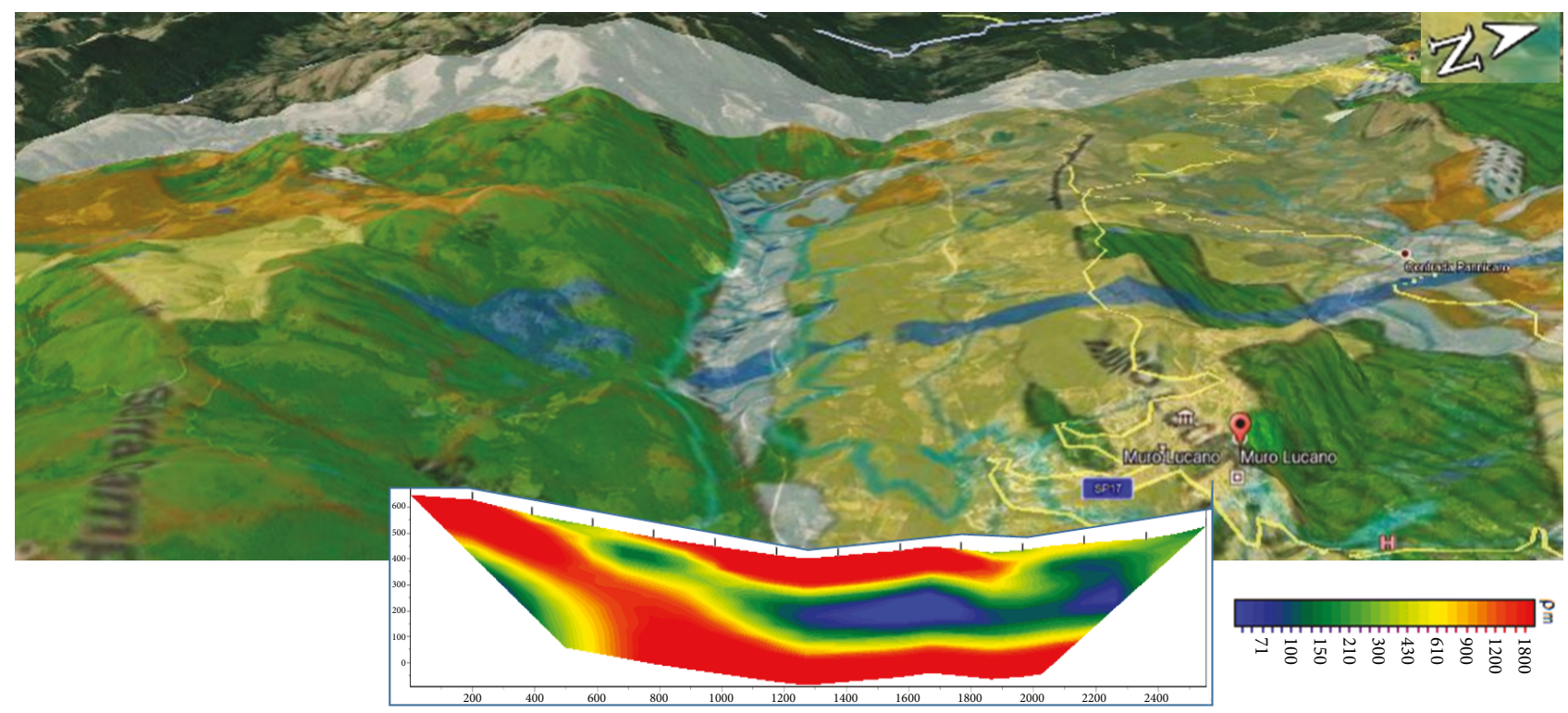

FIgURE 5: The hydrogeological map on a 3D vision (Google 3D) and the DERT image. The deep was carried out by CNR-IMAA prototype. The RMS is $12.8 \%$.
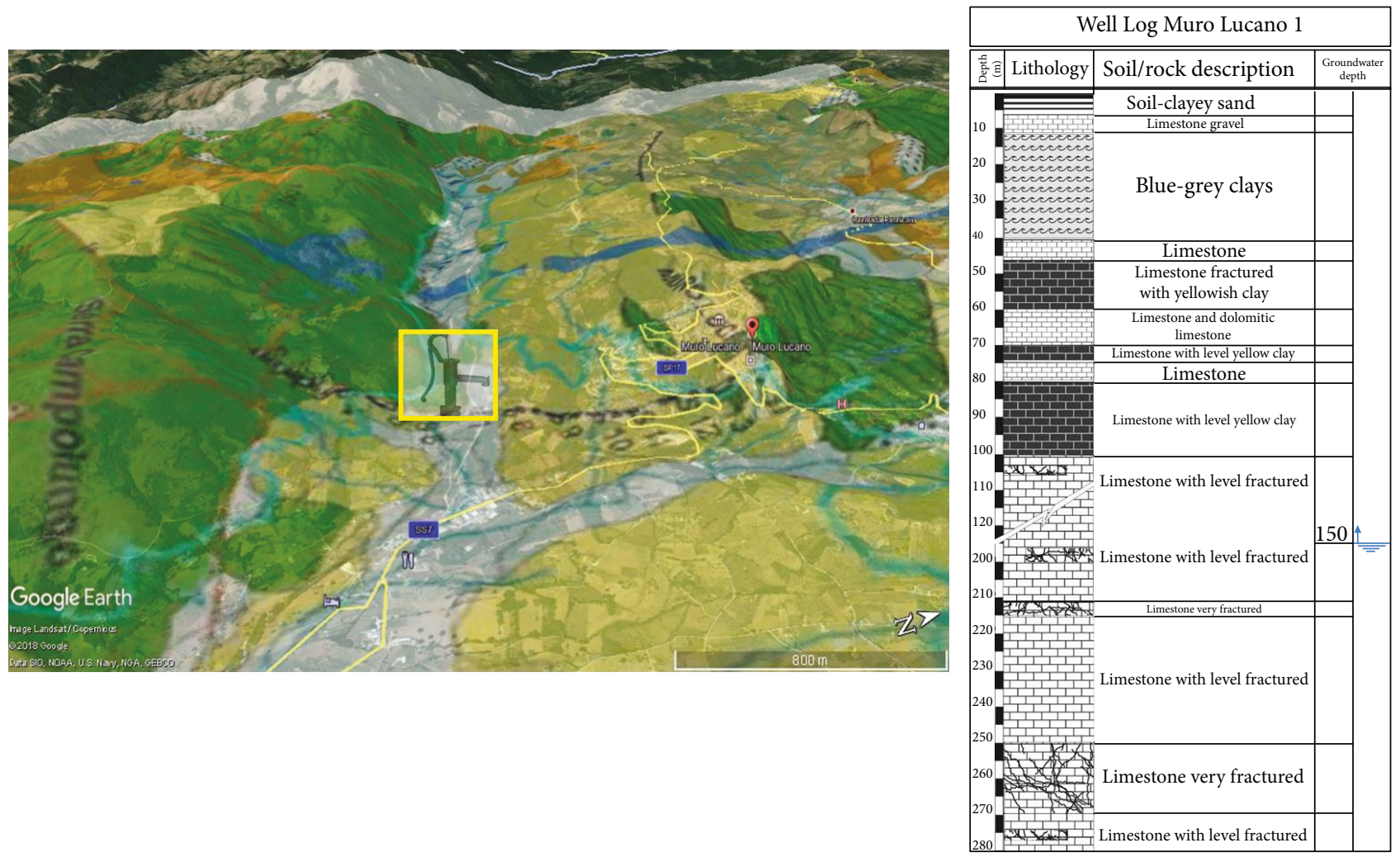

Figure 6: The hydrogeological map and the well log of the Muro Lucano 1 well.

up to the end of the profile, between the electrodes S7 and S8. The well, with a depth of $280 \mathrm{~m}$ from the surface, allowed us to reconstruct the lithological succession along it (well log in Figure 6). In particular, we found a very thick alluvial deposit layer $(10 \mathrm{~m})$, a shallow clay layer (30 m tick) of Sicilide unit, a
$60 \mathrm{~m}$ thick layer of Miocene limestones and clays (Irpinian units), and a thick carbonate succession (from $100 \mathrm{~m}$ to $280 \mathrm{~m}$ ) characterized by a different fracturing degree. Moreover, the water table was at $150 \mathrm{~m}$ from the surface, in correspondence of the more fractured carbonate layer. The 


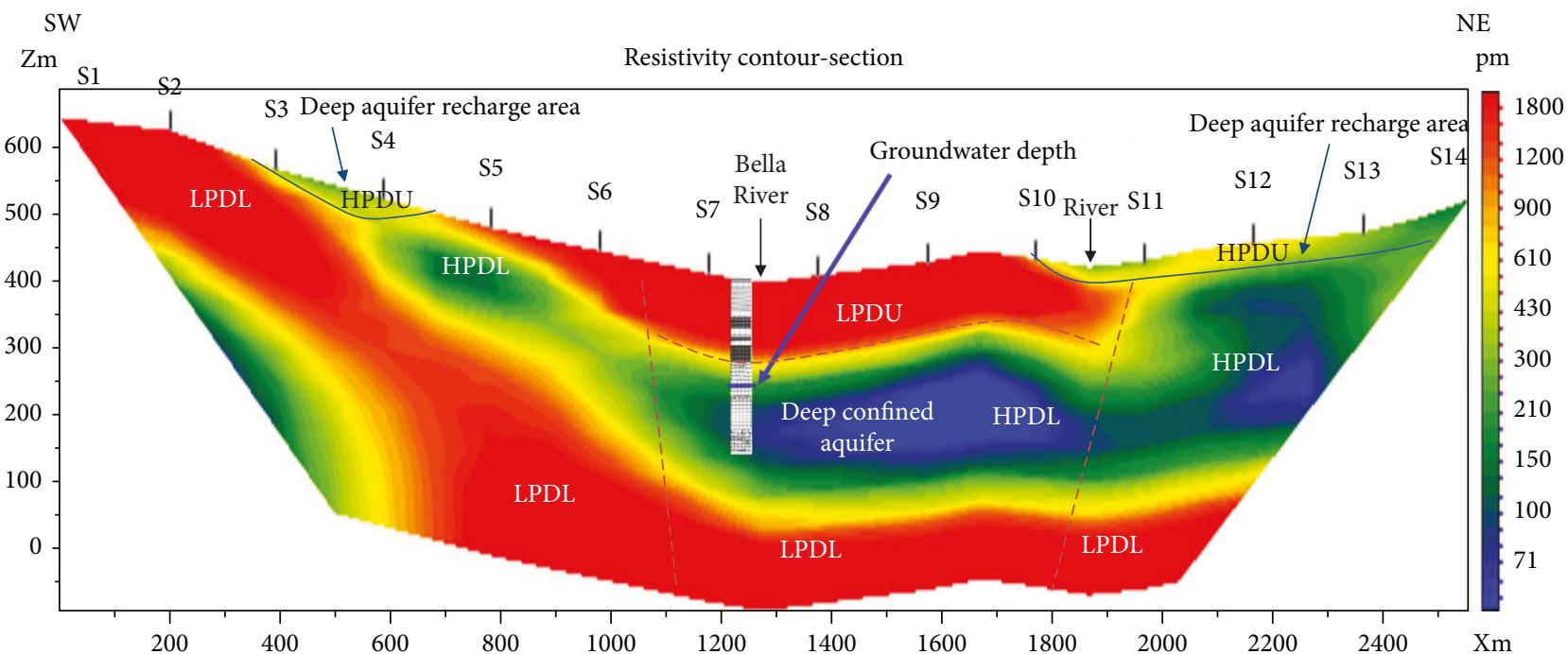

FIGURE 7: The well log applied on the DERT image. Red dotted lines are uncertain fault. HPDU = high permeability degree units; LPDU = low permeability degree units; HPDL = high permeability degree limestones; LPDU = low permeability degree limestones.

aquifer was in pressure, and after the drilling, the water table reached $120 \mathrm{~m}$ from the surface. This phenomenon proved the heterogeneity of the carbonate rock fracture state. Figure 7 shows a comparison between the deep electrical resistivity image and the well geological data. It is very interesting to notice that rocks characterized by a lower permeability degree (Sicilide unit clays and massive limestones) are generally associated to higher resistivity values. Moreover, carbonate rocks on the top and deep define an electrical resistivity range with high values $(>800 \Omega \mathrm{m})$.

In contrast, the carbonate rock with an important fractured state is highlighted in the DERT image with resistivity values $<200 \Omega \mathrm{m}$. According to Kirkby et al. [41], this reflects a decrease in the contribution of the rock matrix resistivity to the passage of current. As fracturing increases, less current passes through the matrix, and therefore, the measured bulk resistivity is more strongly controlled by the fracture network and then by the water resistivity value.

Moreover, the deep groundwater level is localized in correspondence of a relatively deeper conductivity area. Therefore, it is possible to define that the NE shallow conductivity zone is represented by limestone formation with a high level of fractures; on the contrary, the southern limestones have relatively higher resistivity values due to low fracturing level.

Finally, DERT results allow us also to define the deep hydraulic aquifer recharge areas: there is a clear hydraulic connection between the shallower and the deep aquifers in both the N and SE where Pliocene sands and gravel represent a further recharge area of the deep aquifer. However, the deep aquifer is mainly fed by rainwater by outcropping carbonate at the $\mathrm{N}$, with a groundwater flowing in the S-SW direction. In contrast, it seems that there is no hydraulic connection between the southern carbonate massif and the deep Muro Lucano aquifer. This deep water circulation is probably influenced by the local tectonic setting.

\section{Conclusions}

This work shows a useful case study for identifying deep aquifers in carbonate terrains and individuates the best place where to drill a well by using Deep Electrical Resistivity Tomography (DERT). In particular, the exploitation of the Muro Lucano deep aquifer was hampered by the complex geological and hydrogeological situation and by the lack of detailed data. Moreover, the geophysical survey provided more detailed information on buried geological features, aquifer characteristics, deep aquifer recharge zones, and probably conduit and fracture porosity zones along the DERT profile. In particular, the hydrogeological and geophysical analyses describe a high water yield and a not so deep hydrogeological structure which should be tapped to provide the $\mathrm{W}$ sector of the Basilicata region with a huge quantity of water. Moreover, DERT allows us to individuate low resistivity zones that are probably linked to higher permeability hydrogeological units. Finally, from geophysical data, it was shown that the studied hydrogeological structure has a deep and shallow water circulation system connected between them and probably influenced by the local tectonic setting. The future hydrogeological balance will help us to quantify in detail the groundwater resource potentiality for exploitation.

Finally, some general considerations have to be in account. The geological structure, aquifer properties, and groundwater heads are obtained from point measurements (wells and pumping tests) which are sparse, usually available at locations far apart, distances ranging from hundreds to thousands of meters. However, this kind of information in complex aquifers can lead to errors in the conceptual understanding of the aquifer when it is necessary to define the position of an exploitation well. Therefore, the definition of the best site, in terms of maximum efficiency, became a crucial point in the water exploitation. This work would like to show how the ability to make the best geophysical 
investigation in order to reach the described aims is a crucial point for the geophysicist's community. Therefore, this kind of work highlights how the obtained results from a not-common deep electrical resistivity survey (DERT), properly integrated with the geological information, could give a strong information to define the best position of an exploitation well. Moreover, looking the amount of economic resources at stake, a DERT cost is only the $5 \%$ of the total amount for a single well.

\section{Data Availability}

The geoelectrical data used to support the findings of this study are available from one of the authors (Capozzoli Luigi), which is the chief of the Tomogea srl company (info@tomogea.it), that collected the data. The hydrogeological data are available from one of the authors Salvatore Grimaldi.

\section{Conflicts of Interest}

The authors declare that they have no conflicts of interest.

\section{Acknowledgments}

The geoelectrical data were acquired by Tomogea srl, spin-off CNR, and the authors thank the following people who worked during the geoelectrical acquisition work: Marianna Balasco, Massimo Bavusi, Angela Perrone, Sabatino Piscitelli, and Giuseppe Tamburiello.

\section{References}

[1] M. Bakalowicz, "Karst groundwater: a challenge for new resources," Hydrogeology Journal, vol. 13, no. 1, pp. 148160, 2005.

[2] Z. Chen, A. S. Auler, M. Bakalowicz et al., "The World Karst Aquifer Mapping project: concept, mapping procedure and map of Europe," Hydrogeology Journal, vol. 25, no. 3, pp. 771-785, 2017.

[3] A. Hartmann, N. Goldscheider, T. Wagener, J. Lange, and M. Weiler, "Karst water resources in a changing world: review of hydrological modeling approaches," Reviews of Geophysics, vol. 52, no. 3, pp. 218-242, 2014.

[4] T. Bechtel, F. Bosch, and M. Gurk, "Geophysical methods in karst hydrogeology," in Methods in Karst Hydrogeology, N. Goldscheider and D. Drew, Eds., pp. 171-199, Taylor and Francis/Balkema, London, U. K., 2007.

[5] K. Chalikakis, V. Plagnes, R. Guerin, R. Valois, and F. P. Bosch, "Contribution of geophysical methods to karst-system exploration: an overview," Hydrogeology Journal, vol. 19, no. 6, pp. 1169-1180, 2011.

[6] B. Berkowitz, "Characterizing flow and transport in fractured geological media: a review," Advances in Water Resources, vol. 25, no. 8-12, pp. 861-884, 2002.

[7] M. Beres, M. Luetscher, and R. Olivier, "Integration of ground-penetrating radar and microgravimetric methods to map shallow caves," Journal of Applied Geophysics, vol. 46, no. 4, pp. 249-262, 2001.

[8] L. Bermejo, A. I. Ortega, R. Guérin et al., "2D and 3D ERT imaging for identifying karst morphologies in the archaeological sites of Gran Dolina and Galería Complex (Sierra de Atapuerca, Burgos, Spain)," Quaternary International, vol. 433, pp. 393-401, 2016.

[9] F. J. Martínez-Moreno, J. Galindo-Zaldívar, A. Pedrera et al., "Detecting gypsum caves with microgravity and ERT under soil water content variations (Sorbas, SE Spain)," Engineering Geology, vol. 193, pp. 38-48, 2015.

[10] W. Brown, K. Stafford, M. Shaw-Faulkner, and A. Grubbs, “A comparative integrated geophysical study of Horseshoe Chimney Cave, Colorado Bend State Park, Texas," International Journal of Speleology, vol. 40, no. 1, pp. 9-16, 2011.

[11] C. M. Burberry, C. A.-L. Jackson, and S. R. Chandler, "Seismic reflection imaging of karst in the Persian Gulf: implications for the characterization of carbonate reservoirs," AAPG Bulletin, vol. 100, no. 10, pp. 1561-1584, 2016.

[12] E. Cardarelli, M. Cercato, A. Cerreto, and G. Di Filippo, "Electrical resistivity and seismic refraction tomography to detect buried cavities," Geophysical Prospecting, vol. 58, no. 4, pp. 685-695, 2010.

[13] V. Di Fiore, A. Angelino, S. Passaro, and A. Bonanno, "High resolution seismic reflection methods to detect near surface tuff-cavities: a case study in the neapolitan area, Italy," Journal of Cave and Karst Studies, vol. 75, no. 1, pp. 51-59, 2013.

[14] F. J. Martínez-Moreno, J. Galindo-Zaldívar, A. Pedrera et al., "Integrated geophysical methods for studying the karst system of Gruta de las Maravillas (Aracena, Southwest Spain)," Journal of Applied Geophysics, vol. 107, pp. 149-162, 2014.

[15] S. H. Wadas, U. Polom, and C. M. Krawczyk, "High-resolution shear-wave seismic reflection as a tool to image near-surface subrosion structures - a case study in bad Frankenhausen, Germany," Solid Earth, vol. 7, no. 5, pp. 1491-1508, 2016.

[16] E. Cardarelli, G. Di Filippo, and E. Tuccinardi, "Electrical resistivity tomography to detect buried cavities in Rome: a case study," Near Surface Geophysics, vol. 4, no. 15, 2006.

[17] V. Festa, A. Fiore, M. Parise, and A. Siniscalchi, "Sinkhole evolution in the Apulian karst of southern Italy; a case study, with some considerations on sinkhole hazards," Journal of Cave and Karst Studies, vol. 74, no. 2, pp. 137-147, 2012.

[18] V. Giampaolo, L. Capozzoli, S. Grimaldi, and E. Rizzo, "Sinkhole risk assessment by ERT: the case study of Sirino Lake (Basilicata, Italy)," Geomorphology, vol. 253, pp. 19, 2016.

[19] G. Kaufmann, "Geophysical mapping of solution and collapse sinkholes," Journal of Applied Geophysics, vol. 111, pp. 271288, 2014.

[20] R. Martel, P. Castellazzi, E. Gloaguen, L. Trépanier, and J. Garfias, "ERT, GPR, InSAR, and tracer tests to characterize karst aquifer systems under urban areas: the case of Quebec City," Geomorphology, vol. 310, pp. 45-56, 2018.

[21] R. Valois, L. Bermejo, R. Guérin, S. Hinguant, R. Pigeaud, and J. Rodet, "Karstic morphologies identified with geophysics around Saulges caves (Mayenne, France)," Archaeological Prospection, vol. 17, no. 3, pp. 151-160, 2010.

[22] M. Gambetta, E. Armadillo, C. Carmisciano, L. Cocchi, and F. Caratori Tontini, "Determining geophysical properties of a near-surface cave through integrated microgravity vertical gradient and electrical resistivity tomography measurements," Journal of Cave and Karst Studies, vol. 73, no. 1, pp. 11$15,2011$.

[23] T. McCormack, Y. O'Connell, E. Daly, L. W. Gill, T. Henry, and M. Perriquet, "Characterisation of karst hydrogeology in Western Ireland using geophysical and hydraulic modelling 
techniques," Journal of Hydrology: Regional Studies, vol. 10, pp. 1-17, 2017.

[24] A. Seren, A. E. Babacan, K. Gelisli, Z. Ogretmen, and R. Kandemir, "An investigation for potential extensions of the Karaca Cavern using geophysical methods," Carbonates and Evaporites, vol. 27, no. 3-4, pp. 321-329, 2012.

[25] J. Zhu, J. C. Currens, and J. S. Dinger, "Challenges of using electrical resistivity method to locate karst conduits-a field case in the Inner Bluegrass Region, Kentucky," Journal of Applied Geophysics, vol. 75, no. 3, pp. 523-530, 2011.

[26] E. A. Atekwana and E. A. Atekwana, "Geophysical signatures of microbial activity at hydrocarbon contaminated sites: a review," Surveys in Geophysics, vol. 31, no. 2, pp. 247283, 2010.

[27] A. Binley and A. Kemna, "Electrical methods," in Hydrogeophysics, Y. Rubin and S. S. Hubbard, Eds., pp. 129-156, Springer, 2005.

[28] A. Binley, G. Cassiani, R. Middleton, and P. Winship, "Vadose zone flow model parameterisation using cross-borehole radar and resistivity imaging," Journal of Hydrology, vol. 267, no. 3-4, pp. 147-159, 2002.

[29] W. Daily, A. Ramirez, D. LaBrecque, and J. Nitao, "Electrical resistivity tomography of vadose water movement," Water Resources Research, vol. 28, no. 5, pp. 1429-1442, 1992.

[30] D. Dam and S. Christensen, "Including geophysical data in ground water model inverse calibration," Groundwater, vol. 41, no. 2, pp. 178-189, 2003.

[31] V. Giampaolo, E. Rizzo, S. Straface, and M. Votta, "Hydrogeophysics techniques for the characterization of a heterogeneous aquifer," Bollettino di Geofisica Teorica ed Applicata, vol. 52, no. 4, pp. 595-606, 2011.

[32] W. K. Kosinski and W. E. Kelly, "Geoelectric soundings for predicting aquifer properties," Ground Water, vol. 19, no. 2, pp. 163-171, 1981.

[33] L. Slater, M. D. Zaidman, A. M. Binley, and L. J. West, "Electrical imaging of saline tracer migration for the investigation of unsaturated zone transport mechanisms," Hydrology and Earth System Sciences, vol. 1, no. 2, pp. 291-302, 1997.

[34] G. E. Archie, "The electrical resistivity log as an aid in determining some reservoir characteristics," Transactions of the AIME, vol. 146, no. 1, pp. 54-62, 1942.

[35] G. E. Archie, "Classification of carbonate reservoir rocks and petro-physical considerations," AAPG Bulletin, vol. 36, no. 2, pp. 278-298, 1952.

[36] Y. Bernabè, M. Zamora, M. Li, A. Maineult, and Y. B. Tang, "Pore connectivity, permeability, and electrical formation factor: a new model and comparison to experimental data," Journal of Geophysical Research, vol. 116, no. B11, 2011.

[37] F. A. L. Dullien, "Porous media," in Fluids Transport and Pore Structure, Academic Press, 2nd edition, 1992.

[38] P. Glover, "What is the cementation exponent? A new interpretation," The Leading Edge, vol. 28, no. 1, pp. 82-85, 2009.

[39] B. Kozlov, M. H. Schneider, B. Montaron, M. Lagues, and P. Tabeling, "Archie's law in microsystems," Transport in Porous Media, vol. 95, no. 1, pp. 1-20, 2012.

[40] W. Z. Yue and G. Tao, "A new non-Archie model for pore structure: numerical experiments using digital rock models," Geophysical Journal International, vol. 195, no. 1, pp. 282291, 2013.

[41] A. Kirkby, G. Heinson, and L. Krieger, "Relating permeability and electrical resistivity in fractures using random resistor network models," Journal of Geophysical Research: Solid Earth, vol. 121, no. 3, pp. 1546-1564, 2016.

[42] D. Roubinet, J. Irving, and P. Pezard, "Relating topological and electrical properties of fractured porous media: insights into the characterization of rock fracturing," Minerals, vol. 8, no. 1, p. 14, 2018.

[43] P. G. Hallof, On the Interpretation of Resistivity and Induced Polarization Measurements, [Ph.D. Thesis], MIT, Cambridge, 1957.

[44] M. Balasco, P. Galli, A. Giocoli et al., "Deep geophysical electromagnetic section across the upper Aterno Valley: preliminary results after the April 6, 2009 L'Aquila earthquake," Bollettino di Geofisica Teorica ed Applicata, vol. 52, no. 3, pp. 443-455, 2011.

[45] A. Colella, V. Lapenna, and E. Rizzo, "High-resolution imaging of the High Agri Valley basin (Southern Italy) with electrical resistivity tomography," Tectonophysics, vol. 386, no. 1-2, pp. 29-40, 2004.

[46] A. Giocoli, C. Magrì, S. Piscitelli et al., "Electrical resistivity tomography investigations in the Ufita Valley (southern Italy)," Annales de Geophysique, vol. 51, pp. 213-223, 2008.

[47] S. Pucci, R. Civico, F. Villani et al., "Deep electrical resistivity tomography along the tectonically active Middle Aterno Valley (2009 L'Aquila earthquake area, Central Italy)," Geophysical Journal International, vol. 207, no. 2, pp. 967982, 2016.

[48] E. Rizzo, A. Colella, V. Lapenna, and S. Piscitelli, "High-resolution images of the fault-controlled High Agri Valley basin (Southern Italy) with deep and shallow electrical resistivity tomographies," Physics and Chemistry of the Earth, vol. 29, no. 4-9, pp. 321-327, 2004.

[49] E. Rizzo and V. Giampaolo, "New deep electrical resistivity tomography in the High Agri Valley Basin (Basilicata, Southern Italy)," Geomatics, Natural Hazards and Risk, vol. 10, no. 1, pp. 197-218, 2019.

[50] H. Storz, W. Storz, and F. Jacobs, "Electrical resistivity tomography to investigate geological structures of the earth's upper crust," Geophysical Prospecting, vol. 48, no. 3, pp. 455-471, 2000.

[51] K. Suzuki, S. Toda, K. Kusunoki, Y. Fujimitsu, T. Mogi, and A. Jomori, "Case studies of electrical and electromagnetic methods applied to mapping active faults, beneath the thick quaternary," Engineering Geology, vol. 56, no. 1-2, pp. 2945, 2000.

[52] G. Tamburriello, M. Balasco, E. Rizzo, P. Harabaglia, V. Lapenna, and A. Siniscalchi, "Deep electrical resistivity tomography and geothermal analysis of Bradano foredeep deposits in Venosa area (southern Italy): first results," Annals of Geophysics, vol. 51, no. 1, pp. 203-212, 2008.

[53] M. Balasco, A. Giocoli, S. Piscitelli et al., "Magnetotelluric investigation in the High Agri Valley (southern Apennine, Italy)," Natural Hazards and Earth System Sciences, vol. 15, no. 4, pp. 843-852, 2015.

[54] G. Romano, M. Balasco, A. Siniscalchi, E. Gueguen, Z. Petrillo, and S. Tripaldi, "Geological and geo-structural characterization of the Montemurro area (Southern Italy) inferred from audiomagnetotelluric survey," Geomatics, Natural Hazards and Risk, vol. 9, no. 1, pp. 1156-1171, 2018.

[55] E. Patacca and P. Scandone, "Geology of the Southern Apennines," Bollettino della Società Geologica Italiana, vol. 7, pp. 75-119, 2007. 
[56] C. Doglioni, F. Mongelli, and P. Pieri, "The Puglia uplift (SE Italy): an anomaly in the foreland of the Apenninic subduction due to buckling of a thick continental lithosphere," Tectonics, vol. 13, no. 5, pp. 1309-1321, 1994.

[57] E. Gueguen, C. Doglioni, and M. Fernandez, "On the post-25 Ma geodynamic evolution of the Western Mediterranean," Tectonophysics, vol. 298, no. 1-3, pp. 259-269, 1998.

[58] P. Shiner, A. Beccacini, and S. Mazzoli, “Thin-skinned versus thick-skinned structural models for Apulian carbonate reservoirs: constraints from the Val d'Agri Fields, S Apennines, Italy," Marine and Petroleum Geology, vol. 21, no. 7, pp. 805-827, 2004.

[59] A. M. Noguera and G. Rea, "Deep structure of the Campanian - Lucanian Arc (Southern Apennine, Italy)," Tectonophysics, vol. 324, no. 4, pp. 239-265, 2000.

[60] P. Scandone, A. Mazzotti, G. L. Fradelizio et al., Line CROP 04: Southern Apennines, Mem. Descr. Carta Geol. d'It., LXII, 2003.

[61] D. Scrocca, S. Sciamanna, E. Di Luzio, M. Tozzi, C. Nicolai, and R. Gambini, "Structural setting along the CROP-04 deep seismic profile (Southern Apennines - Italy)," Bollettino della Società geologica italiana, vol. 7, pp. 283-296, 2007.

[62] T. Pescatore, P. Renda, M. Schiattarella, and M. Tramutoli, "Stratigraphic and structural relationships between MesoCenozoic Lagonegro basin and coeval carbonate platforms in southern Apennines, Italy," Tectonophysics, vol. 315, no. 1-4, pp. 269-286, 1999.

[63] F. Ortolani, E. Cocco, E. Cravero et al., "Le Unità Irpine nell'Area a nord di Monte Marzano, Appennino Meridionale," Mem. Soc. Geol. It., vol. 13, pp. 607-654, 1974.

[64] A. Ascione, A. Cinque, L. Improta, and F. Villani, "Late Quaternary faulting within the Southern Apennines seismic belt: new data from Mt. Marzano area (Southern Italy)," Quaternary International, vol. 101-102, pp. 27-41, 2003.

[65] A. Marangella, G. Indelli, M. Mastrangelo, A. Miccoli, M. Parise, and S. M. Valdes, "La condotta forzata della diga sul Torrente S. Pietro (Muro Lucano, Basilicata)," Memorie dell'Istituto Italiano di Speleologia, vol. 2008, pp. 478483, 2008.

[66] V. Del Gaudio and J. Wasowski, Stima a Scala Regionale della Probabilità Temporale di Innesco Sismico di Frane in Irpinia, GNGTS - Atti del $21^{\circ}$ Convegno Nazionale / 04.19, 2002.

[67] V. Lapenna, M. Macchiato, D. Patella, C. Satriano, C. Serio, and V. Tramutoli, "Statistical analysis of non-stationary voltage recordings in geoelectrical prospecting," Geophysical Prospecting, vol. 42, no. 8, pp. 917-952, 1994.

[68] D. W. Marquardt, "An algorithm for least-squares estimation of nonlinear parameters," Journal of the Society for Industrial and Applied Mathematics, vol. 11, no. 2, pp. 431-441, 1963. 

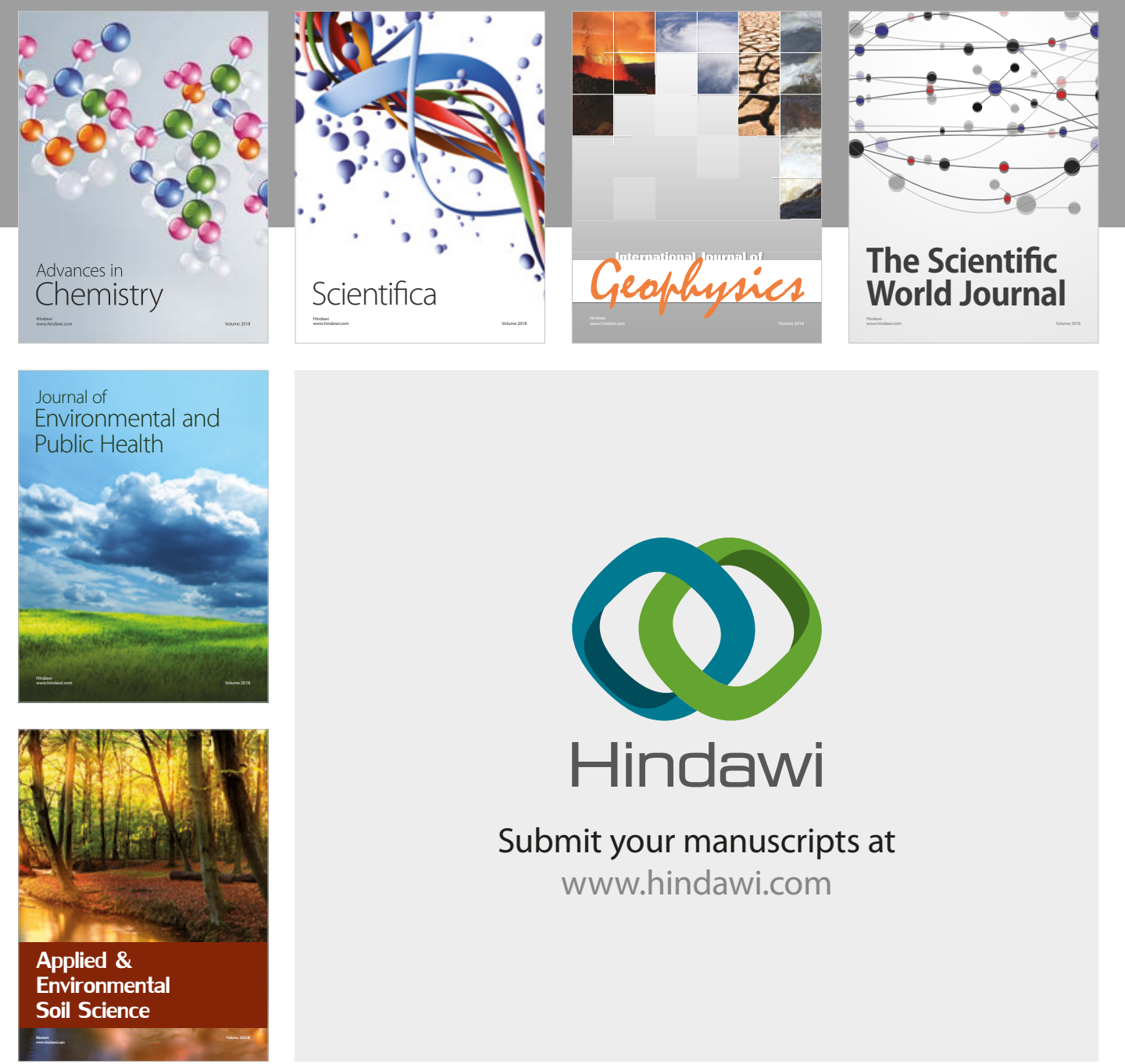

The Scientific

\section{World Journal}
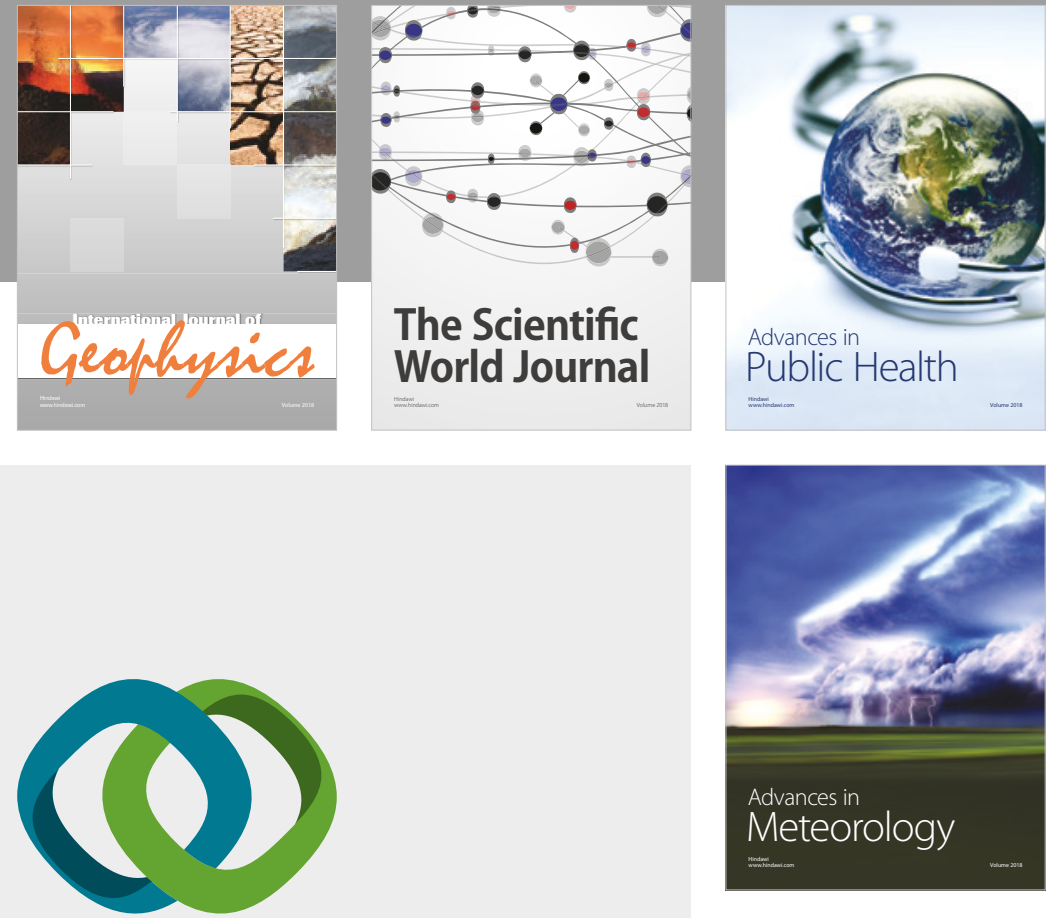

Advan

Public Health

\section{Hindawi}

Submit your manuscripts at

www.hindawi.com
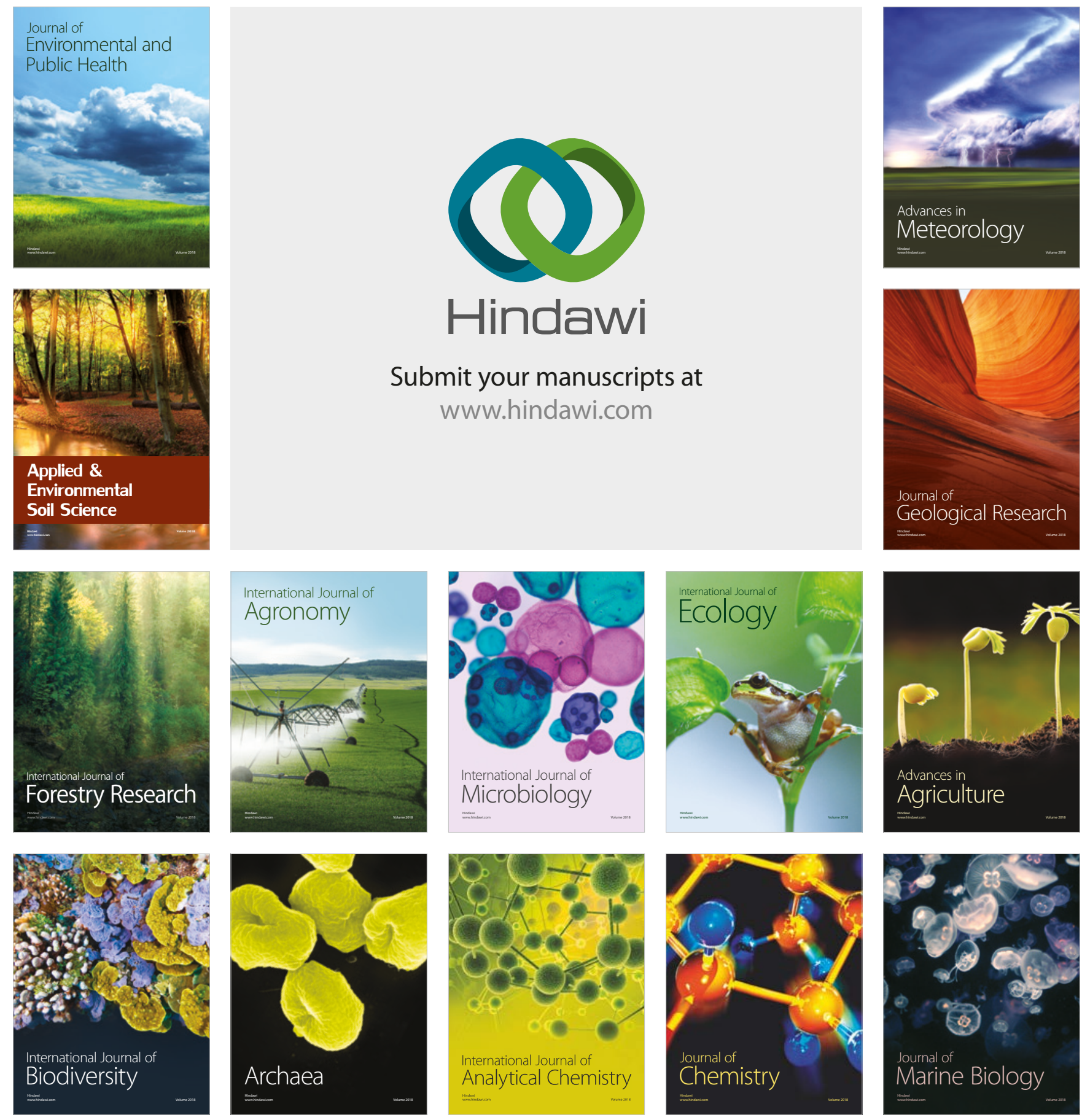